\title{
Discussion on the Combination of Sports and New Media in the New Era
}

\author{
Maria Turgeneva ${ }^{1}$ Yiyi Zhang ${ }^{2, *}$
}

\author{
${ }^{1}$ Taras Shevchenko National University of Kyiv, Kiev, Ukraine \\ ${ }^{2}$ Moscow Pedagogical State University, Moscow, Russia \\ ${ }^{*}$ Corresponding author.
}

\begin{abstract}
With the development of society, the sports economy system is constantly improving and the sports industry is developing rapidly on the basis of social development. In recent years, the growth rate of the economic output value of the sports industry has obvious advantages compared with the growth rate of other industries at the same stage. It can be said that the development of the sports industry is also a component of social and economic development. And the rapid development of the modern sports industry is inseparable from the efficient combination of media technology. In the context of the rapid development of new media, new media and TV (television) media are indispensable ways for the communication of sports culture to achieve an effective combination of sports and media. And the organic combination and application of the two is an important trend in the development of sports media.
\end{abstract}

Keywords: new era, sports, media, sports culture

\section{INTRODUCTION}

The rapid development of the sports industry is inseparable from the efficient combination of new media technology. With the rapid updating and popularization of advanced Internet technology and new media equipment among people, society is entering a new period of information resource interaction. The new media can bring a large amount of information resources to the sports industry and provide a medium for the rapid dissemination of sports information.

However, with the rapid popularization of Internet technology, new media has penetrated into the lives of the people. The International Olympic Committee's website http://www.olympic.org/ can provide high resolution photos, Video News Releases (VNRs), press releases, information on accreditation, a calendar of events, etc. In today's new media era, the living space of traditional media such as television and newspapers was once squeezed from the Internet media. For example, the development and promotion of the sports industry in mobile terminals has continued to reduce the total number of TV users. In addition, the Internet is also changing the channels of information dissemination. Nowadays, people can obtain information through WeChat and microblog, which further drains traditional media users.

But nowadays, the information dissemination of sports culture and the construction of the sports industry can't do without the support of traditional media. Therefore, how to efficiently combine traditional television media with new media to maximize the effect of promoting the development of sports industry is undoubtedly a major problem that needs to be resolved.

II. WAYS TO COMBINE SPORTS AND MEDIA IN THE NEW MEDIA ERA: EFFECTIVE INTEGRATION OF NEW MEDIA AND TRADITIONAL MEDIA

The difference between today's sports media and the 20 th century is that the interactivity of online social media has been greatly enhanced, and the Internet can give people more freedom and more ways of expression when watching sports events. On the one hand, people can learn about the latest sports information through the emerging online media, and on the other hand, they can break away from the limitation of unilaterally accepting information by traditional media, and can express their opinions and standpoints with their subjective initiative, and they can also interact with people in the online community in this process. In the 2018 Rio Olympics, mobility, video and interactivity have become the biggest features of Olympic reporting.

In the era of new media, in addition to professional media and reporters, anyone on the scene can become a producer and disseminator of primary information. The content of self-media may not be inferior to any professional media, even more original and richer. Social media allows everyone to participate in the 
discussion of the Olympics and evoke more user interaction. The survey shows that the index of viewers following the Olympics through WeChat, search engines, and video sites is approaching TV. New media such as social networking sites have become the main channels for young people to pay close attention to the Olympics.

However, in addition to the new media audience, the receivers of sports information also have traditional television audiences. Although today's young people are more willing to learn about sports information from mobile and computer terminals, there are still a considerable number of older audiences that have difficulty getting rid of the habit of watching sports events on TV and understanding sports information.

This shows that traditional media still has value for the development of the sports industry. Therefore, while people are playing the role of new media in the construction of the sports industry, they can't ignore the role of traditional media. Instead, it's necessary to combine the two through effective means to give full play to the role of the media in the sports industry, and better combine the media with sports.

However, as mentioned in the previous article, the living space of television media is now being squeezed from online media. Therefore, if sports and media want to be better integrated, firstly, it is necessary to effectively integrate traditional sports media and new media in many aspects.

\section{A. The information fusion between TV media and new media}

The biggest advantage of new media is that information is released in a timely manner and audiences can easily obtain information through PC and mobile terminals. For example, the public can see the news updates of various sports teams at the first time through the Internet, and obtain timely information and sports reviews of many Chinese and foreign athletes. The multiple channels of the Internet give users more choices in obtaining information. However, technology is always a double-edged sword, and while creating value, it will also expose its own shortcomings. The new media has brought countless sports learning to the audience, but this information is mixed, and some unofficial information can't ensure its authenticity.

Therefore, in order to effectively integrate traditional sports media and new media, it's needed to realize the complementation of resources at the information level. From a practical point of view, there are already a lot of traditional TV media and new media for commercial cooperation. Television media improves real and effective learning for new media to make up for the lack of authenticity of new media information.
For example, the sports client-side of Internet TV has multiple columns such as program lists of major sports games, live or on demand events and exclusive comments by the host and so on. In addition, there are various sports events, which complement and integrate sports information resources from multiple aspects. And they let the traditional television media obtain brand-new vitality through the new carrier.

\section{B. The complementation and integration of the communication form content of TV media and new media}

Another outstanding advantage of new media over TV media is that it is highly interactive. Internet users can participate in various activities related to sports events in new media, and they can also communicate and discuss with other users who may not know each other in real life in the online community, which is difficult for television media to do.

Judging from the development history of TV media, TV media has also done prize-winning guessing activities through telephone calls and text messages, but this form of interaction has been difficult to attract users with the advent of network technology. Therefore, TV media needs to make good use of their brand influence to further innovate the form of interaction and communication. For example, the CCTV Sports Channel has opened its own columns on microblog, WeChat official account and sports forums to create distinctive and open programs, increase audience participation, and further increase the influence of its own brand. [3]

\section{The complementation and integration of the communication channels of TV media and new media}

New media can make use of the brand influence and credibility of resources possessed by traditional sports television media, and traditional sports television media can use the communication technology of new media to complement each other. For example, a new media platform and Guangdong Sports Channel once cooperated to let viewers see more international competitions. Not only did this increase the ratings of Guangdong Sports Channel, but the new media platform also stood out among similar platforms and gained more attention.

In general, in the context of the rapid development of new media, both new media and television media are indispensable ways for the spread of sports culture. The organic combination and application of the two is an important trend in the development of sports media. When new media and traditional media have their own advantages and disadvantages, this can scientifically realize the sustainable and long-term development of sports media through complementary advantages. 


\section{ECONOMIC AND SOCIAL BENEFITS OF COMBINING SPORTS WITH MEDIA IN THE NEW MEDIA ERA}

The further combination of sports and new media can dig deeper into the potential market of the sports industry.

The development of media can bring more added value to the sports industry. For example, the global sports information integration technology launched by Internet technology has brought more market and economic benefits to the sports industry.

The new media carnival triggered by the 2018 Rio Olympics is leading the Internet industry to use sports competitions to explore a new model of its entire industry chain layout. In the future, some Internet giants will continue to acquire high-quality event resources, and they may also try to infiltrate all copyrights of event operations and team shares. However, it is certain that a new industrial chain is being created and integrated by new media, and the new media in the future will surely play an important role in the formation of this industrial chain.

Now, entering the 2020s, the number of media that can be combined with sports has further increased. For example, Hupu and other sports information apps that include a variety of sports forms and content of sports events provide smartphone users with more effective and practical information services. In recent years, there have been more and more mobile phone users. Compared with the client-side, consumers are more willing to get the latest sports information from mobile media anytime and anywhere. From another perspective, mobile media can allow consumers to purchase tickets for each event more conveniently and bring more revenue to the hosting of sports events. In addition, the development of media technology can also enable information audiences to have a better experience. For example, Alisports and CCTV Sports Channel not only sponsor the Hangzhou International Marathon, but also introduce high-tech technologies such as traffic intelligence brains, driverless technology and face scan payment to help the 2022 Hangzhou Asian Games "go to the cloud", break through the space constraints, give play to the superimposed effect of technology and industry, and bring a brand new experience for audiences. [4]

Therefore, while mobile media brings more audiences to the sports industry, it also gains more means for its own profitability.

Looking back at the entire process of combining media and sports, from newspapers to TV, from computer websites to mobile phone software, the media has been updating. However, consumers' spiritual and cultural needs and material needs related to the sports industry have not decreased, but will even continue to increase with the development of sports. While the development of the media has met the needs of consumers, it has also brought more and more economic and social benefits to the development of the entire sports industry. Therefore, it can be seen that the advancement of media technology and effective integration with the sports industry can bring more business opportunities to the society, allowing the potential of the advancing sports market to be continuously dug.

\section{CONCLUSION}

In summary, the efficient combination of increasingly improved media technology and sports has promoted the rapid development of the sports industry.

To combine the two, traditional TV media and new media must be effectively integrated in the three levels of information, communication channels and cost forms.

From an impact perspective, in the context of the new media era, the combination of sports and media will bring positive feedback to the society. It is mainly reflected in the role of the media in disseminating the unique culture of the sports industry, bringing huge social benefits to the society, further integrating sports and media, digging into the potential market of the sports industry and creating economic benefits.

The times will continue to progress, and the new media is also in a process of continuous development. In order to achieve long-term development of the sports industry, it is necessary to combine new media and sports in accordance with the development trend of the times, keep trying and actively put into practice.

\section{References}

[1] Gu Yanjun. The complementation and integration of new media and sports TV $[\mathrm{J}]$. Science and Technology Communication, 2020,012(002): 111-112. (in Chinese)

[2] Li Qian. Social media, the best combination of brand and sports [J]. China Advertising, 2012,000(007): P.29-30. (in Chinese)

[3] Hu Dujuan. "Internet + sports": research on the media convergence mode of CCTV5+ and Alisports [J]. A Vast View on Publishing, 2020,000(004): 76-78. (in Chinese)

[4] Li Tianzhi, Chou Hui. Research on the development path of Chinese sports industry in the new media era [J]. Stationery and Sports Supplies and Technology, 2020,002(002): 51-52. (in Chinese)

[5] Peng Xunwen. What does it mean for new media to exert force for the Olympics? Earth-shaking changes in information channels. http://media.people.com.cn/ (in Chinese)

[6] https://www.olympic.org/news/media-resources 